\title{
The fetal electrocardiogram to detect the effects of betamethasone on fetal heart rate variability.
}

\section{Citation for published version (APA):}

Noben, L., Verdurmen, K. M. J., Warmerdam, G. J. J., Vullings, R., van Laar, J., \& Oei, G. (2019). The fetal electrocardiogram to detect the effects of betamethasone on fetal heart rate variability. Early Human Development, 130, 57-64. https://doi.org/10.1016/j.earlhumdev.2019.01.011

\section{Document license:}

TAVERNE

DOI:

10.1016/j.earlhumdev.2019.01.011

Document status and date:

Published: 01/03/2019

\section{Document Version:}

Publisher's PDF, also known as Version of Record (includes final page, issue and volume numbers)

\section{Please check the document version of this publication:}

- A submitted manuscript is the version of the article upon submission and before peer-review. There can be important differences between the submitted version and the official published version of record. People interested in the research are advised to contact the author for the final version of the publication, or visit the $\mathrm{DOI}$ to the publisher's website.

- The final author version and the galley proof are versions of the publication after peer review.

- The final published version features the final layout of the paper including the volume, issue and page numbers.

Link to publication

\section{General rights}

Copyright and moral rights for the publications made accessible in the public portal are retained by the authors and/or other copyright owners and it is a condition of accessing publications that users recognise and abide by the legal requirements associated with these rights.

- Users may download and print one copy of any publication from the public portal for the purpose of private study or research.

- You may not further distribute the material or use it for any profit-making activity or commercial gain

- You may freely distribute the URL identifying the publication in the public portal.

If the publication is distributed under the terms of Article 25fa of the Dutch Copyright Act, indicated by the "Taverne" license above, please follow below link for the End User Agreement:

www.tue.nl/taverne

Take down policy

If you believe that this document breaches copyright please contact us at:

openaccess@tue.nl

providing details and we will investigate your claim. 


\title{
The fetal electrocardiogram to detect the effects of betamethasone on fetal heart rate variability ${ }^{\text {is }}$
}

\author{
L. Noben ${ }^{\mathrm{a}, \mathrm{c}, *}$, K.M.J. Verdurmen ${ }^{\mathrm{a}, \mathrm{c}}$, G.J.J. Warmerdam ${ }^{\mathrm{b}, \mathrm{c}}$, R. Vullings ${ }^{\mathrm{b}, \mathrm{c}}$, S.G. Oei $^{\mathrm{a}, \mathrm{b}}$, \\ J.O.E.H. van Laar ${ }^{\mathrm{a}, \mathrm{c}}$ \\ a Department of Obstetrics and Gynecology, Maxima Medical Center, Veldhoven, the Netherlands \\ ${ }^{\mathrm{b}}$ Department of Electrical Engineering, Eindhoven University of Technology, Eindhoven, the Netherlands \\ ${ }^{\mathrm{c}}$ Eindhoven MedTech Innovation Center (e/MTIC), Eindhoven, the Netherlands
}

\section{A R T I C L E I N F O}

\section{Keywords:}

Fetal heart rate variability

Corticosteroids

Betamethasone

Fetal electrocardiogram

\begin{abstract}
A B S T R A C T
Background: Betamethasone is widely used to enhance fetal lung maturation in case of threatened preterm birth. Antenatal corticosteroids are known to reduce fetal heart rate variability (fHRV) in the days following administration. Since decreased fHRV is a marker for fetal distress, this transient decrease of fHRV can cause unnecessary medical intervention.

Aim: To describe the effect of betamethasone on fHRV, by applying spectral analysis on non-invasive fetal electrocardiogram (fECG) recordings.

Study design: Secondary analysis of a prospective cohort study.

Subjects: Women with a singleton pregnancy, at risk for preterm delivery and receiving betamethasone, admitted to the obstetric high care unit in the period from March 2013 until July 2016.

Outcome measures: The primary outcome measure was fHRV in both time- and frequency-domain. Secondary outcome measures included basal fetal heart rate (fHR) and fHR variance. FHRV parameters were then calculated separately for the quiet and active state.

Results: Following 68 inclusions, 22 patients remained with complete series of measurements and sufficient data quality. FHRV parameters and fHR showed a decrease on day 2 compared to day 1, significant for short-term variability and high-frequency power. Similar results were found when analyzing for separate behavioral states. The number of segments in quiet state increased during days 1 and 2. Normalized values showed no difference for all behavioral states.

Conclusion: FHRV decreases on day 2 after betamethasone administration, while periods of fetal quiescence increase. No changes were found in the normalized values, indicating that the influence of autonomic modulation is minor.

Clinical trial registration number

NL43294.015.13
\end{abstract}

\section{Introduction}

Corticosteroids significantly reduce neonatal morbidity and mortality and are widely used in case of impending premature delivery [1]. Betamethasone is the most frequently used corticosteroid, and is administered between 24 and 34 weeks of gestation. The effects of betamethasone on fetal heart rate variability (fHRV) were thoroughly researched during the last two decades. A transient decrease in fHRV, most pronounced on day two after administration, has been repeatedly established [2-6]. This effect is of clinical significance since fHRV is an important parameter of fetal wellbeing [7]. Decreased variability can be misinterpreted as fetal distress, causing unnecessary iatrogenic preterm birth. Therefore, thorough knowledge of these effects is warranted.

Fetal heart rate (fHR) and thus fHRV are regulated by a complex interplay between the sympathetic and parasympathetic nervous

\footnotetext{
* This research was performed within the framework of the Eindhoven MedTech Innovation Center (e/MTIC). e/MTIC had no role in the study design, collection,

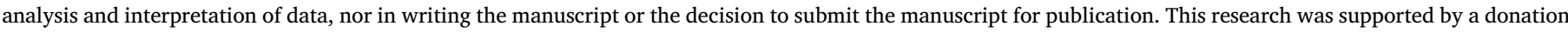
made by Stichting de Weijerhorst to the Máxima Medical Center for scientific purposes.

* Corresponding author at: Máxima Medisch Centrum, Postbus 7777, 5500 MB Veldhoven, the Netherlands.

E-mail address: lore.noben@mmc.nl (L. Noben).
} 


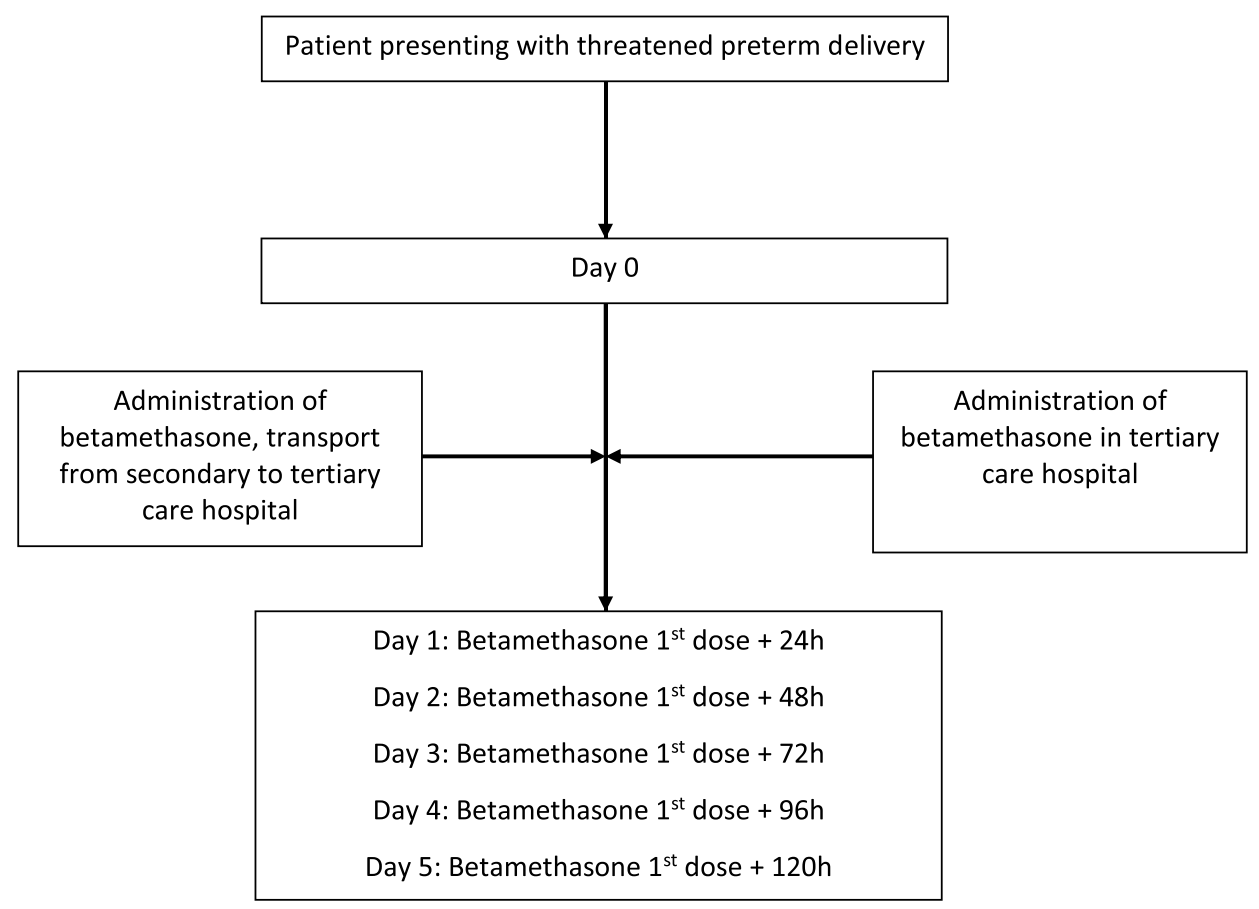

Fig. 1. Flowchart of patient inclusion and timing of measurements.

system. This autonomic regulation of fHRV can be estimated by means of spectral analysis [8]. Fetal electrocardiography (fECG) can be measured non-invasively from the maternal abdomen [9]. It provides beatto-beat information on the fHR, making analysis of fHR variability through spectral analysis possible.

The currently used method for fetal monitoring, the cardiotocogram (CTG) is highly dependent on visual assessment by the physician. Therefore, agreement between observers (inter-observer reliability) and even within the same observer (intra-observer reliability) is poor [10]. This technique measures fHR by means of doppler-ultrasound, averaging the fHR over several heartbeats. Beat-to-beat information on the $\mathrm{fHR}$, necessary to perform spectral analysis, is lacking.

Verdurmen et al. previously reported on the effect of betamethasone administration on spectral values of fHRV [11]. At that time, only $42.8 \%$ of the collected data was of sufficient quality for analysis. Due to an improvement of the data processing algorithm, we were able to increase this amount of data to $70.9 \%$. In this paper we will re-evaluate the effect of betamethasone on overall fHRV values. In addition we evaluated the effect of fetal behavioral states on fHRV.

\section{Materials and methods}

The results presented in this paper are derived from the previously published study by Verdurmen et al. [11]. A detailed description of the study methods can be found in their paper. A prospective longitudinal cohort study was performed at the Máxima Medical Center Veldhoven, The Netherlands. This is a tertiary care hospital for obstetrics. The local Medical Ethical Committee approved the study protocol. Participants were included after written informed consent.

\subsection{Study population}

Women with a singleton pregnancy, receiving betamethasone (Celestone Chrondose ${ }^{\circledR}$, Schering AG, Berlin, Germany; 2 doses of $12 \mathrm{mg}$ intramuscularly, $24 \mathrm{~h}$ apart) as part of standard clinical management were eligible to participate. Concomitant use of other medication was allowed. Exclusion criteria were maternal age under 18 years, multiple pregnancy, fetuses with a known congenital malformation, signs of intra-uterine infection of fetal growth restriction (i.e. estimated weight of the fetus below the 5th percentile for gestational age).

\subsection{Outcome measures}

The primary outcome was fHRV, which is a function of the fluctuation of the R-R interval (length between two successive $R$ waves). We quantified fHRV using both time-domain features (short-term variability [STV] and long-term variability [LTV]) and frequency-domain features (low-frequency (LF-) and high-frequency (HF-) power) [12-14]. STV is sensitive to changes in successive heartbeats and is calculated based on the difference between successive inter-beat intervals $[15,16]$. LTV gives a measure for the overall variability in the heart rate, and is calculated as the difference between the maximum and minimum inter-beat interval within a one-minute period [16]. LFand HF-power reflect the energy in specific frequency components. High-frequency (HF-) power is associated with respiratory activity and regulated by the parasympathetic nervous system. Low-frequency (LF-) power is mediated by both the sympathetic and the parasympathetic branches of the autonomic nervous system and reflects the baroreceptor reflex $[8,17]$.

As secondary outcomes, we calculated the fHR (in beats per minute, $\mathrm{bpm})$. In addition, we calculated fHR variance. FHR variance is calculated as the square of the standard deviation of the fHR and reflects the variation around the mean heart rate for each $60 \mathrm{~s}$ segment (in bpm). Based on the fHR variance, segments can be classified into periods of quiet state (fHR variance $<15 \mathrm{bpm}^{2}$ ) and periods of active state (fHR variance $>30 \mathrm{bpm}^{2}$ ) $[12,14,18]$.

FHRV parameters were first calculated for the overall measurement and then separately for both quiet and active state.

\subsection{Measurements}

We performed series of fetal electrocardiographic (fECG) measurements as visualized in Fig. 1. Each measurement lasted approximately $30 \mathrm{~min}$. No CTG measurements were performed during the fECG measurement, and the output of the fECG measurements was not available for healthcare givers. Complete series were defined as series including a 


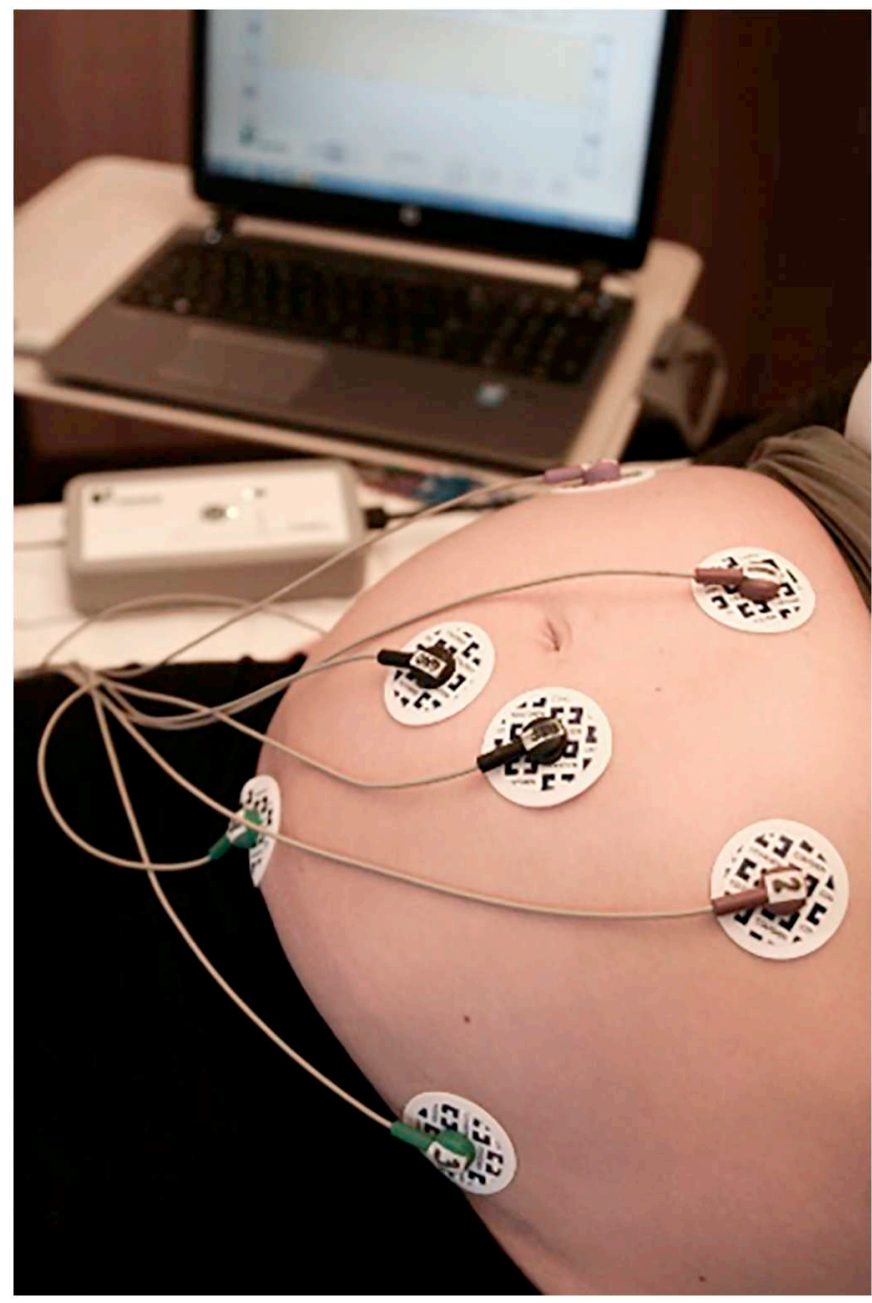

Fig. 2. The fetal electrocardiogram.

reference measurement, and measurements during at least days 1, 2, and 3. In case one or more of these measurements was missing, the patient was excluded. A baseline measurement was performed before the administration of betamethasone (day 0, 0-measurement). When betamethasone treatment was started in secondary care hospitals prior to transport to our center, no baseline measurement was available. Literature shows that fHR and fHRV values return to baseline on day 4 ( $96 \mathrm{~h}$ after the first dose of betamethasone) [19]. Therefore, we used the median value of the measurements during day 0 , and/or day 4 , and/or day 5 as the "reference measurement".

\subsection{Data acquisition and signal processing}

We used two non-invasive electrophysiological monitoring devices: a prototype version of the Nemo fetal monitoring system (Nemo Healthcare BV, Eindhoven, the Netherlands) and the Porti system (TMSi, Enschede, the Netherlands). Approval of the Medical Technical Service Department of the Máxima Medical Center was obtained. Eight electrodes were placed on the maternal abdomen in a fixed configuration (Fig. 2), including one ground and one reference electrode.

The recordings from the previously published study were re-analyzed offline [11]. Recordings were first pre-processed to suppress the maternal ECG using a dynamic template subtraction technique [20]. The signals remaining after maternal ECG suppression were spatially combined to enhance the signal-to-noise ratio of the fetal ECG with respect to remaining electrophysiological interferences (e.g. muscle activity). Finally, fetal $\mathrm{R}$ peak detection was performed using an adaptive ECG model to obtain a beat-to-beat fHR [21].

Prior to fHRV analysis, the obtained heart rates were automatically analyzed for incorrect R-R intervals. R-R intervals shorter than $0.3 \mathrm{~s}$ or longer than $1.2 \mathrm{~s}$ ( $<50$ or $>200 \mathrm{bpm}$ ) were assumed to be incorrect [22]. Furthermore, if an R-R interval deviated $>12 \%$ from a running average R-R interval, it was also assumed to be incorrect [23]. The incorrect R-R intervals were replaced by linear interpolation. To ensure reliable spectral analysis, only heart rate segments of $60 \mathrm{~s}$ were included with $<20 \%$ interpolation and $<5$ s of consecutive interpolation [23]. We only included measurements with at least three segments that met the quality criteria.

\subsection{Heart rate variability analysis}

Spectral analysis is performed using a continuous wavelet transform. Since spectral analysis requires signals that are equidistantly distributed in time, the obtained heart rates are resampled at $4 \mathrm{~Hz}$ by linear interpolation. Spectral power bands are defined based on previous studies: total frequency $0.04-1.5 \mathrm{~Hz}, \mathrm{LF} \quad 0.04-0.15 \mathrm{~Hz}$ and $\mathrm{HF}$ $0.4-1.5 \mathrm{~Hz}[8,14,24-27]$. LF- and HF-power was expressed in absolute units $\left(\mathrm{ms}^{2}\right)$ and normalized units. Normalized values were calculated by dividing LF and HF power by total power (LFn = LF-power / total power, HFn = HF-power / total power). Due to this normalization, relative changes in LF- and HF-power are not affected by changes in total power.

To compare our results to prior research performed with CTG measurements, STV and LTV were calculated in addition to spectral analysis. LTV was calculated as the difference between the maximum and minimum R-R interval in every $60 \mathrm{~s}$ segment $[28,29]$. STV was calculated as the mean of absolute differences between consecutive R-R intervals in every $60 \mathrm{~s}$ segment [28]. Note that STV in Doppler monitoring is defined based on epochs (e.g. 1/16th of a minute) because beat-to-beat fHR is not possible with this technique. However, since the gold standard for STV is beat-to-beat variation, we used the aforementioned ECG-based STV calculation.

\subsection{Statistical analysis}

A Wilcoxon-signed rank test was used to study significant changes between the measurement days for each HRV parameter. We compared the median value of each parameter on each measurement day to the reference measurement as well as the remaining days. We used the Bonferroni correction to correct for multiple testing. Thus, a probability value of 0.0083 was calculated as the significance level $(p=0.05 / 6)$. We calculated a Spearmans rho coefficient to test whether the fHRV parameters on day 2 were influenced by the time of day at which the measurement had been performed.

\section{Results}

Initially, 68 women were included in this study. Three patients requested withdrawal from the study, one because of poor prognosis for an extreme premature child, one because of technical problems with the measuring equipment and one because of inconvenient timing of measurements for the patient. In one patient unexpected intra-uterine death occurred during the study period. Extensive evaluation revealed no evident cause. In 33 patients the measurement series was not completed due to discharge from the hospital or delivery $(\mathrm{N}=17)$, the presence of a congenital heart disease $(N=1)$ or arrythmia $(N=1)$, intra-uterine growth retardation $(\mathrm{N}=1)$, interrupted measurement sequence $(\mathrm{N}=2)$ or clinical evaluation revealed corticosteroid administration was no longer necessary after the reference measurement on day 0 had already taken place $(\mathrm{N}=6)$. From the remaining 31 complete series, 8 were excluded due to insufficient data quality. One patient was excluded later on due to loss to follow-up. 22 patients with a complete set of sufficient data quality were included for analysis. 
Table 1

Baseline characteristics.

$\begin{array}{ll}\text { No. patients } & 22 \\ \text { Maternal characteristics } & \\ \text { GA (wk) on admittance } & 28.4 \pm 3.1 \\ \text { Gravidity } & 2(1-3) \\ \text { Parity } & 1(0-1) \\ \text { BMI } & 25.4 \pm 5.6 \\ \text { Smoking (\%) } & 4.5 \\ \text { Medication (\%) } & \\ \text { Nifedipine } & 63.3 \\ \text { Indomethacin } & 4.5 \\ \text { Atosiban } & 4.5 \\ \text { Indication CCS (\%) } & \\ \text { TPL } & 36.4 \\ \text { VBL } & 31.8 \\ \text { PPROM } & 22.7 \\ \text { PE } & 4.5 \\ \text { PPROM }+ \text { VBL } & 4.5 \\ \text { Neonatal characteristics } & \\ \text { GA (wk) at birth } & 34.7 \pm 4.7 \\ \text { Birthweight (in grams) } & 2487.7 \pm 991.9 \\ \text { Apgar } 1 \text { min (N = 19) } & 9(7-9) \\ \text { Apgar } 5 \text { min (N = 21) } & 10(9-10) \\ \text { NICU admittance (\%) } & 22.7 \\ \end{array}$

Data provided are percentages or means \pm SD. Median (interquartile range) are provided for variables that are not normally distributed.

Abbreviations: $\mathrm{GA}=$ gestational age, $\mathrm{BMI}=$ body mass index, $\mathrm{CCS}=$ corticosteroids, $\quad \mathrm{TPL}=$ threatened preterm labor, $\mathrm{VBL}=$ vaginal blood loss, $\mathrm{PPROM}=$ premature prelabor rupture of membranes, $\mathrm{PE}=$ pre-eclampsia, $\mathrm{NICU}=$ neonatal intensive care unit.

Table 1 shows the baseline characteristics of this group.

\subsection{Primary outcome}

Our primary outcome was changes in HRV during corticosteroid treatment. Fig. 3 shows the changes of the different fHRV parameters over the study period.

We found an increasing trend of both STV and LTV on day 1 , and a decreasing trend on day 2 compared to the reference measurement, which is comparable to the previously published results by Verdurmen et al. [11]. Due to the small amount of complete data sets available, they only performed descriptive statistics. We found a significant decrease in STV on day 2 compared to day 1 in our enlarged dataset (p 0.002). Absolute spectral values showed the same trend. We found a significant decrease in HF-power on day 2 compared to day 1 (p 0.002). Normalized LF and HF showed little changes during the study period.

Fetal HRV parameters were then calculated separately for recorded segments during quiet and active state (Fig. 4). For the quiet state, sufficient data was available from 18 of the included patients. There was a similar increasing trend visible on day 1 for STV and LTV as well as LF- and HF-power. Furthermore, we found a significant decrease in STV on day 2 compared to day 1 (p 0.005) during the quiet state. For the active state only 7 complete datasets were available and no significant results were observed.

\subsection{Secondary outcome}

Fig. 5 shows the changes seen in fHR during the study period. It shows a significant decrease on day 1 compared to the reference measurement (p 0.001) as well as a significant increase on day 3 compared to day 1 (p 0.006).

Fig. 6 shows the fHR variance over the study period. There is a clear decrease on day 2 . The changes in periods in quiet (fetal heart rate variance $<15 \mathrm{bpm}^{2}$ ) and active (fetal heart rate variance $>30 \mathrm{bpm}^{2}$ ) state are shown in Fig. 7. The number of segments in quiet state increase on days 1 and 2, while the number of segments in active state decrease. On day 4 the number of segments in quiet and active state returns back to premedication values.

We found no correlation between the time of day of the measurements and the fHRV parameter values (Table 2).
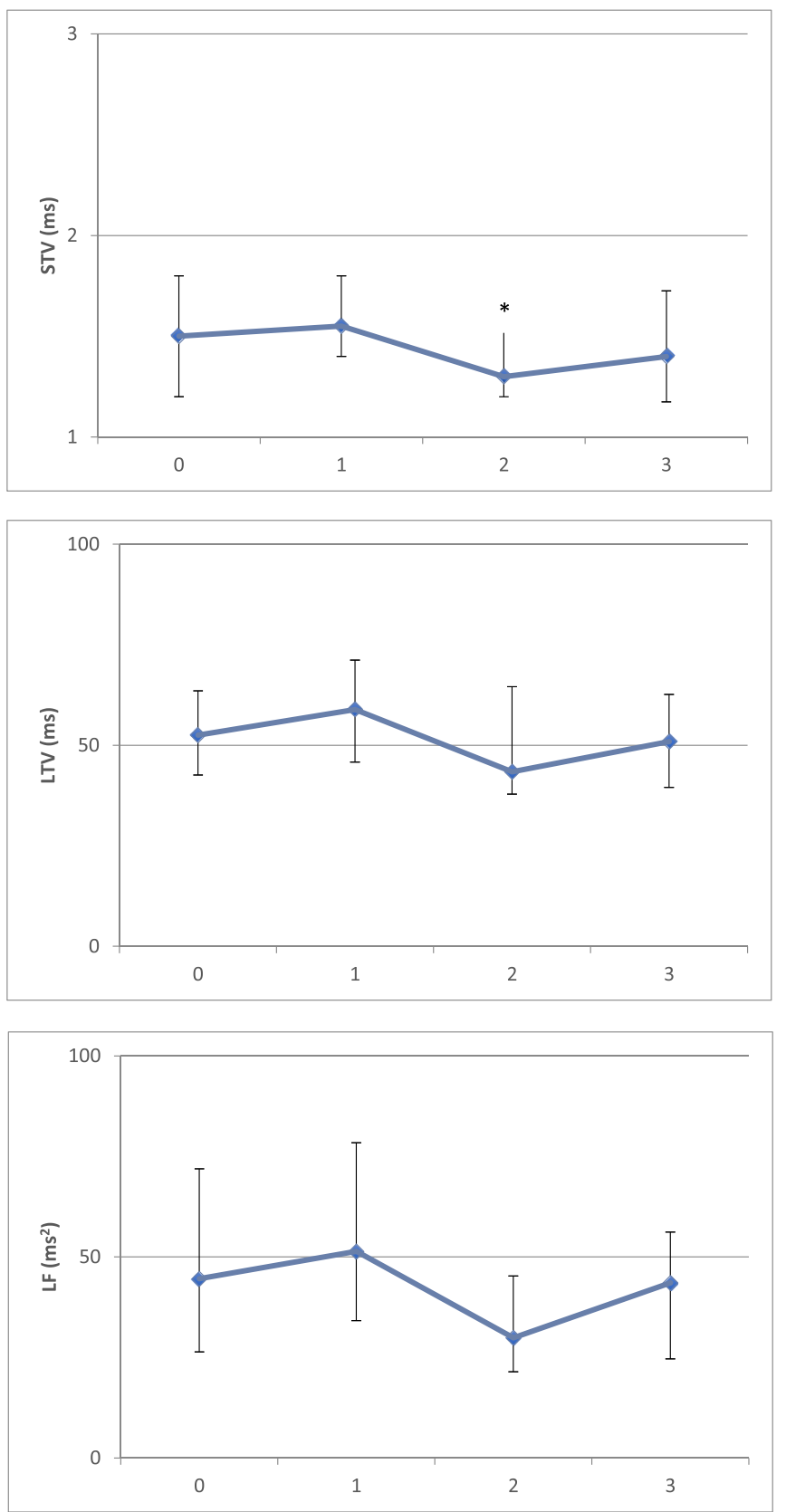

Fig. 3. Changes in the fetal heart rate variability parameters during the study period.

Median values with interquartile ranges are shown for the reference day and day 1,2 and 3 after the first betamethasone administration (x-axis). Day 0 is the median value of the measurements during day 0 , and/or day 4 , and/or day 5 . $*=$ statistically significant difference relative to day 1 .

Abbreviations: STV $=$ short-term variability, $\mathrm{LTV}=$ long-term variability, $\mathrm{LF}=$ low-frequency power, $\mathrm{HF}=$ high-frequency power, $\mathrm{LFn}=$ normalised low-frequency power, $\mathrm{HFn}=$ normalised high-frequency power. 

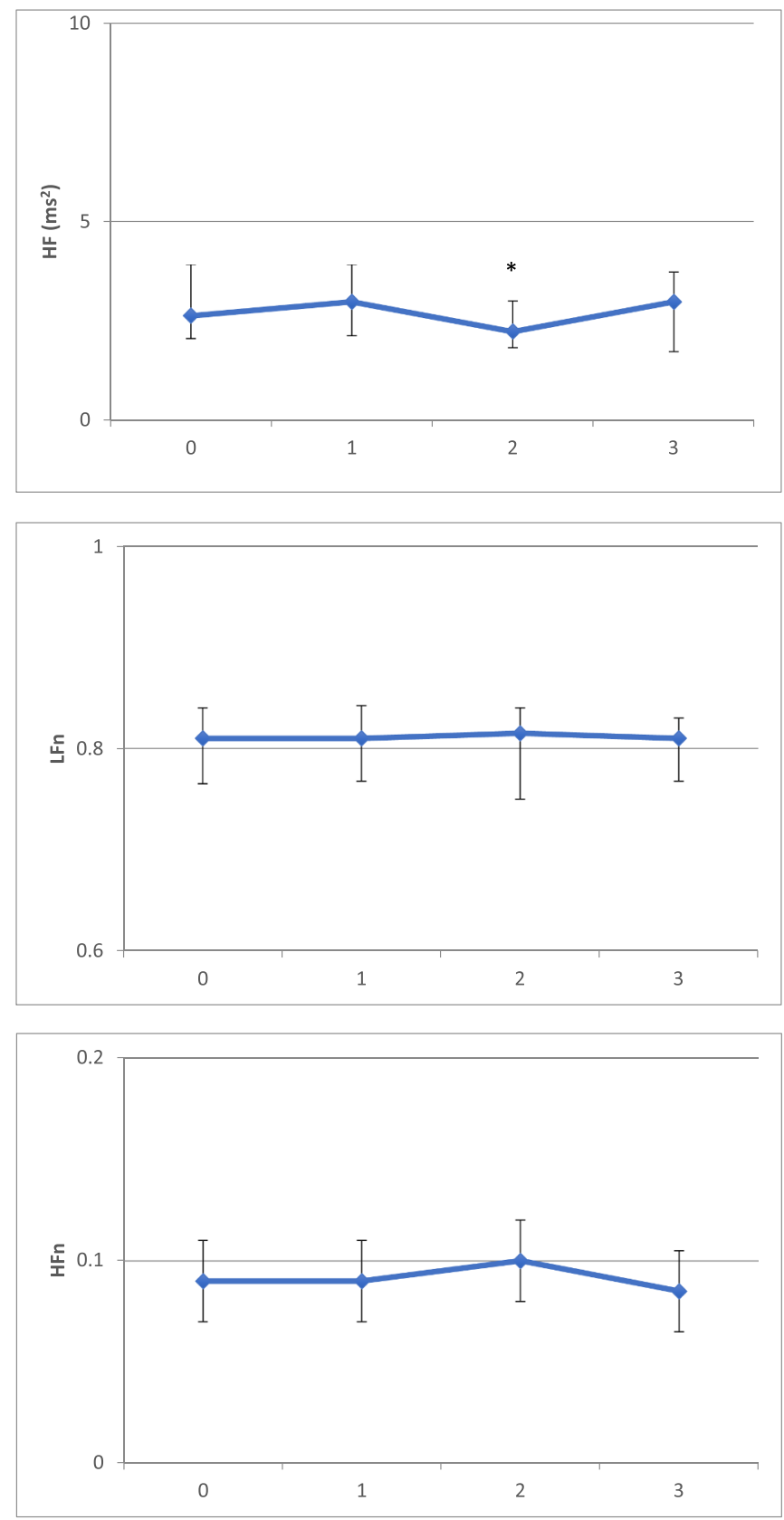

Fig. 3. (continued)

\subsection{Segments available for analysis}

Table 3 shows the amount of segments available for analysis. Due to algorithm improvements these percentages are considerably higher than before, except for day 0 [11].

\section{Discussion}

We found similar results compared to previous studies where fHRV was evaluated using CTG analysis [19]. STV and LTV values decrease $48 \mathrm{~h}$ after the first betamethasone administration, before returning to baseline values on day 4 [2,3]. By using non-invasive abdominal ECG recordings for fetal monitoring, we were able to obtain beat-to-beat information of the fHR. This enabled us to use spectral analysis for measuring HRV in the frequency domain. LF- and HF-power are absolute spectral estimates that relate well to respectively LTV and STV. As expected, they show a similar trend during our study period. In adults, the use of normalized values is recommended since they reflect relative changes [30]. Both our LFn and HFn values showed little changes during the study period, indicating that the influence of autonomic modulation is minor.

Besides changes in variability parameters, we found a small but significant decrease in basal fHR on day 1 , which has been previously described in other studies performed with CTG data [2,3,5,31-33]. Although significant, the clinical value of this small difference (149 bpm on the reference day compared to $143 \mathrm{bpm}$ on day 1 ) can be disputed. Furthermore, it is known that fHRV and fHR are inversely correlated $[4,31,33,34]$. Although an increasing trend on day 1 can be noticed in our fHRV parameters, these results are not significant.

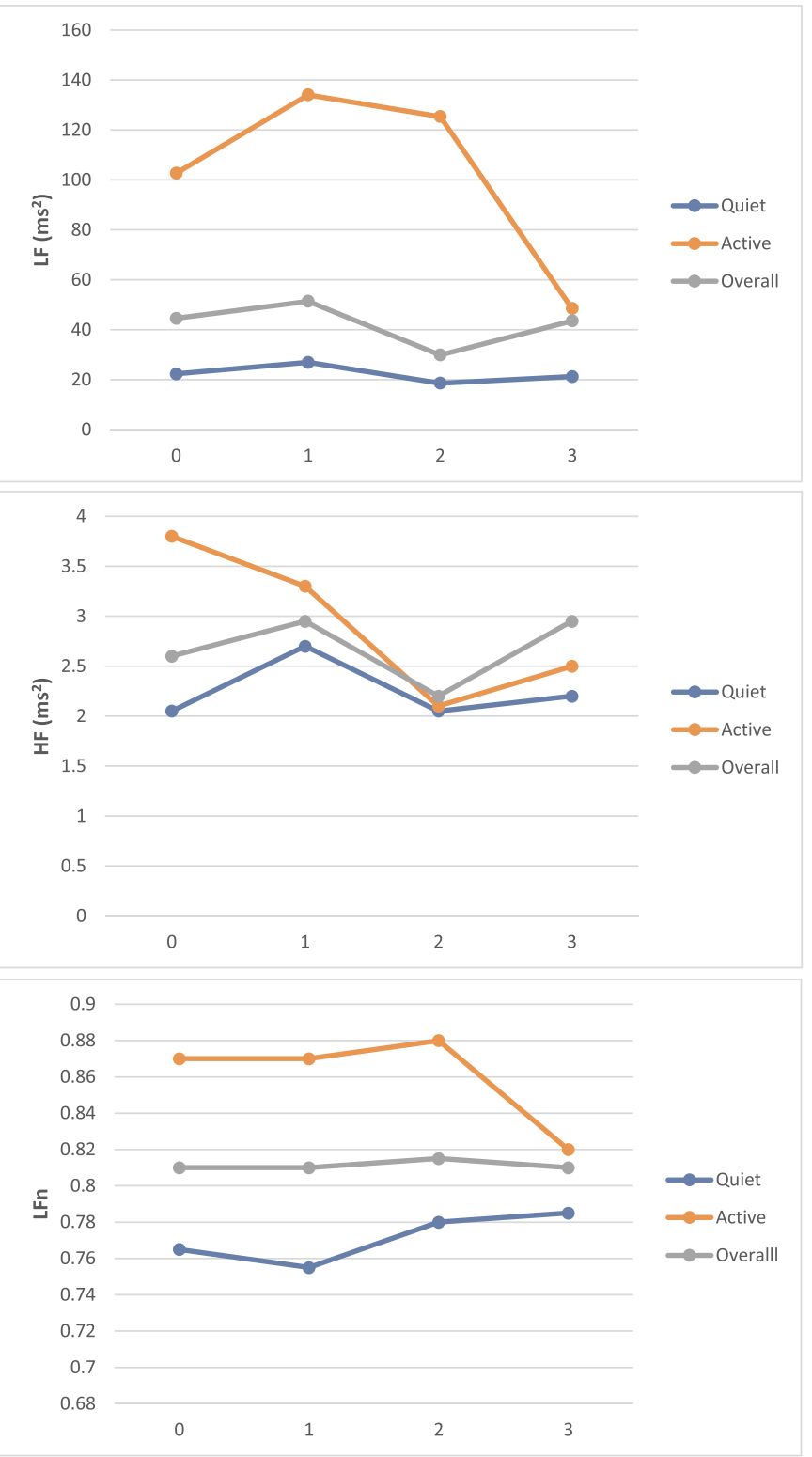

Fig. 4. Changes in the fetal heart rate variability parameters during the study period for active and quiet state.

Median values are shown for the reference day and day 1,2 and 3 after the first betamethasone administration (x-axis), for quiet and active state separately as well as combined for all fetal behavioral states. Day 0 is the median value of the measurements during day 0 , and/or day 4 , and/or day 5 .

* = statistically significant difference relative to day 1 .

Abbreviations: STV $=$ short-term variability, LTV $=$ long-term variability, $\mathrm{LF}=$ low-frequency power, $\mathrm{HF}=$ high-frequency power, $\mathrm{LFn}=$ normalised low-frequency power, $\mathrm{HFn}=$ normalised high-frequency power. 


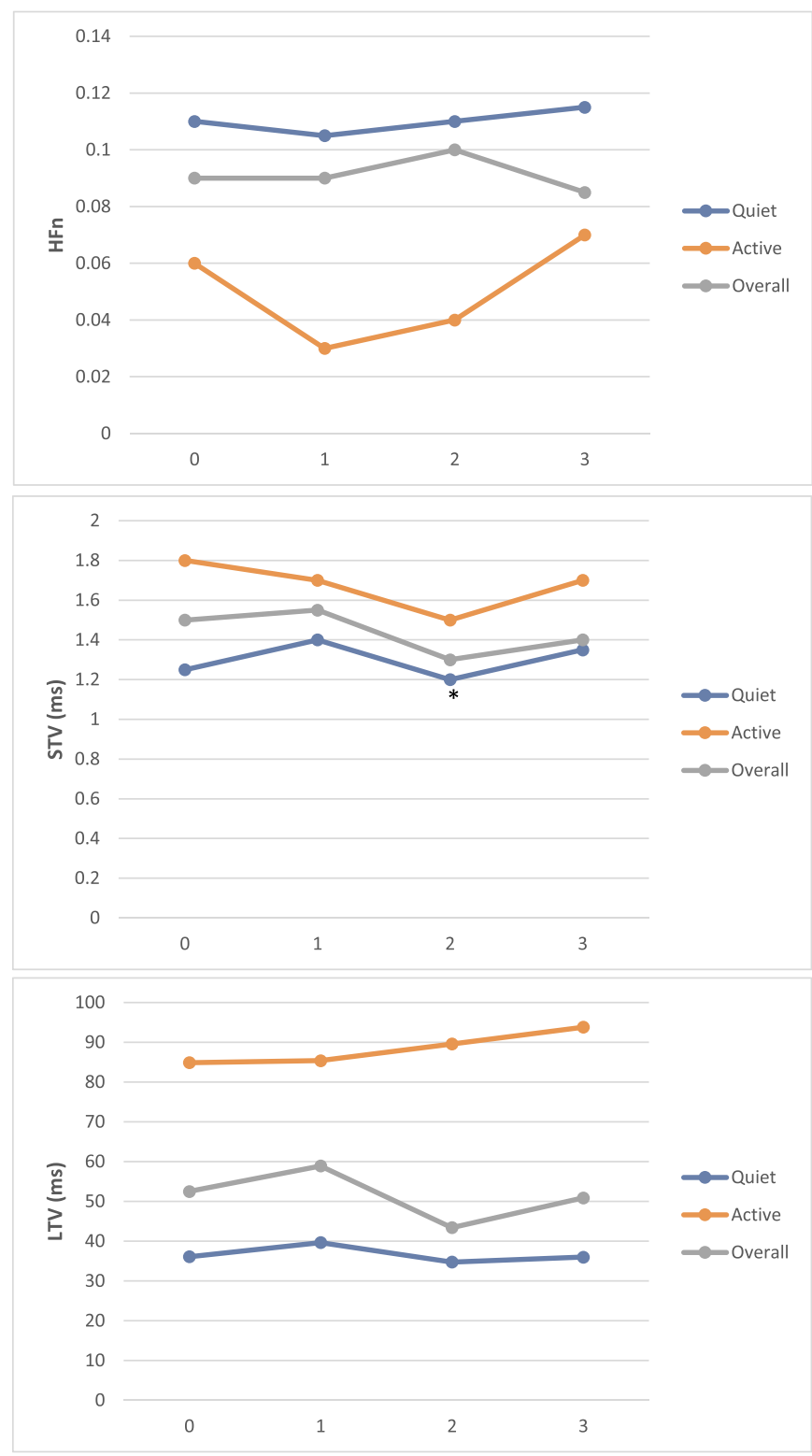

Fig. 4. (continued)

The subsequent increase in basal fHR on day 2 and 3, described by Mulder et al. cannot be confirmed by our results [2,33]. This might be due to the low number of series included, or by the fact that CTG uses averaging over several heartbeats, which can influence the results.

Due to an improvement of the algorithm, ten additional complete series could be included in our analysis. This increased the total amount of data available for analysis from $18 \%$ to $32 \%$. This is still a relative small proportion due to loss-to-follow up (56\%) and insufficient data quality (12\%). We applied a high standard for good signal quality; only measurements containing at least three segments with good signal quality per measurement were selected. When looking at the number of complete measurement series, $71 \%$ was of sufficient quality for analysis, compared to only $43 \%$ in the previously published paper. Due to this increase we found it relevant to re-analyze our data.

Our results confirm the decrease in overall fHRV parameters following betamethasone administration as previously described by Verdurmen et al. [11]. Due to the larger dataset available for analysis, the decrease of STV and HF on day 2 compared to the reference measurement became significant (Fig. 3) [11].

In current daily clinical practice, fHRV (assessed by CTG

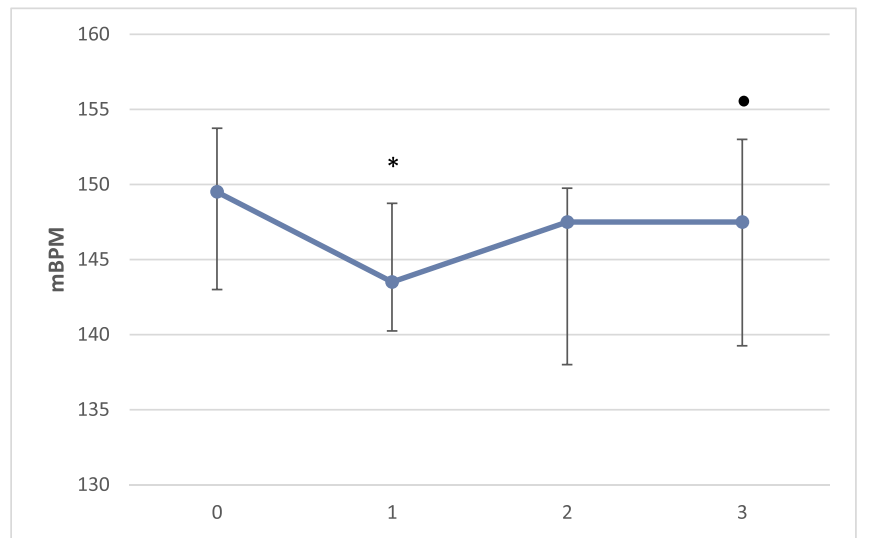

Fig. 5. Changes in fetal heart rate during the study period.

Median values with interquartile ranges are shown for the reference day and day 1, 2 and 3 after the first betamethasone administration (x-axis). Day 0 is the median value of the measurements during day 0 , and/or day 4, and/or day 5 . * = statistically significant difference relative to day 0

- statistically significant difference relative to day 1

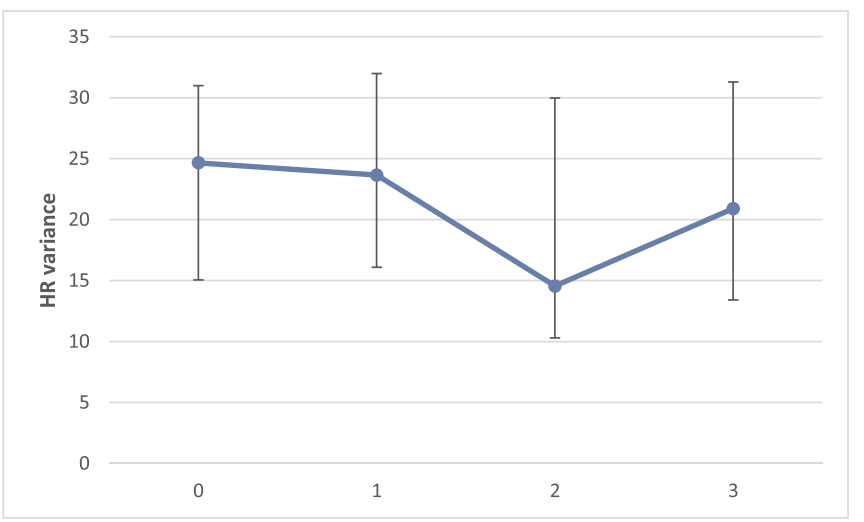

Fig. 6. Changes in heart rate (HR) variance.

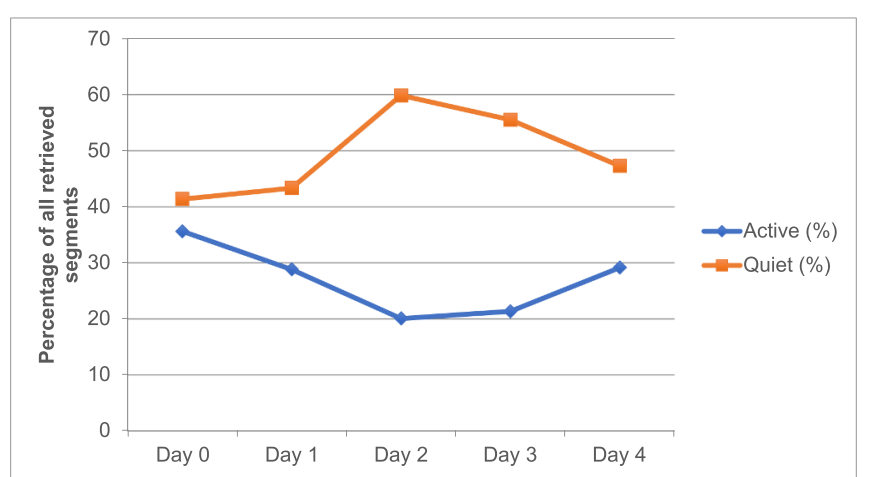

Fig. 7. Changes in periods in quiet and active state.

interpretation) and fetal body movements are important parameters for evaluating fetal wellbeing. The decrease in fHRV, maximal on day 2 of betamethasone treatment, is substantiated by a decrease in fetal body movements reported by mothers and confirmed with ultrasound measurements in previous studies [2,3,35]. Like Verdurmen et al., we confirmed this decrease in fHRV parameters (in time and frequency domain) on day 2 [11]. We also found an increase in number of segments retrieved during periods of quiet state on day 2 (Fig. 7).

This transient decrease in fHRV parameters following betamethasone administration can be misinterpreted as fetal distress, resulting in 
Table 2

Spearman's rank correlation between the time of day of the measurements and the fetal heart rate variability parameters.

\begin{tabular}{lllllll}
\hline & LF & HF & LFn & HFn & STV & LTV \\
\hline $\begin{array}{l}\text { Correlation coefficient } \\
p \text {-Value }\end{array}$ & -0.01 & -0.12 & -0.04 & -0.23 & -0.03 & -0.05 \\
& 0.98 & 0.61 & 0.87 & 0.30 & 0.90 & 0.83 \\
\hline
\end{tabular}

A probability value (p-value) of 0.05 is used as the cutoff for significance. Abbreviations: $\mathrm{LF}=$ low-frequency, $\mathrm{HF}=$ high-frequency, $\mathrm{LFn}=$ normalized low-frequency, HFn = normalized high-frequency, STV = short-term variability, LTV = long-term variability.

Table 3

Amount of segments available for analysis.

\begin{tabular}{llll}
\hline & $\begin{array}{l}\text { Segments available for } \\
\text { analysis/total recorded } \\
\text { segments }\end{array}$ & $\begin{array}{l}\text { Percentage of segments available for } \\
\text { analysis }\end{array}$ & \\
\cline { 2 - 4 } & & Current paper & Verdurmen et al. \\
\hline \multicolumn{2}{l}{ Reference measurement } & & \\
Day 0 & $174 / 249$ & $70 \%$ & $94 \%$ \\
Day 4 & $518 / 714$ & $73 \%$ & $66 \%$ \\
Day 5 & $306 / 487$ & $63 \%$ & $58 \%$ \\
Day 1 & $571 / 674$ & $85 \%$ & $57 \%$ \\
Day 2 & $528 / 769$ & $69 \%$ & $53 \%$ \\
Day 3 & $528 / 751$ & $70 \%$ & $55 \%$ \\
\hline
\end{tabular}

On the remaining study days, measurements were performed in all 22 patients.

a Day 0: measurements performed in 8 out of 22 patients.

b Day 5: measurements performed in 16 out of 22 patients.

unwarranted iatrogenic delivery. To prevent unnecessary preterm delivery, thorough knowledge about this effect of betamethasone on fHRV is crucial. Previous studies on the presence of other indices for fetal distress found no increase of fHR decelerations or changes in Doppler flow indices of various blood vessels after betamethasone administration $[36,37]$. Shenhav et al. also demonstrated there was no relation between fetal acid-base balance and reduced fHRV in fetuses that were born $<48 \mathrm{~h}$ after betamethasone administration [38]. Therefore, the observed transient changes in fHRV parameters are unlikely due to fetal distress.

Since spectral power estimates are known to reflect the autonomic modulation after birth, we aimed to gain more insight into the role of the fetal autonomic nervous system in fHRV changes following betamethasone administration. Fetal autonomic fluctuations, and thus fHRV, are known to be influenced by fetal behavioral states [9]. Van Laar et al. previously found a decrease in fHRV in the frequency domain during quiet state compared to active state [9]. We calculated the fHRV parameters separately for both the active and the quiet state to gain more insight in the suppressive effect of betamethasone. The fHRV values in the quiet state show little variation over the study period. Therefore, it seems likely that the observed changes in fHRV parameters found are due to decreased fetal movements. This hypothesis is also supported by the fact that betamethasone crosses the placenta and is believed to bind to glucocorticosteroid receptors in the fetal brain [19]. These receptors show a high affinity to synthetic glucocorticosteroids and suppress neuronal activity when occupied, leading to increased fetal quiescence [2].

The number of available complete datasets is considerably lower during the active state. This can be due to a low signal-to-noise ratio caused by fetal movement or merely because, due to betamethasone treatment, the fetus spends less time in the active state, leading to a decreased number of segments for this state. Fig. 7 pleads for the latter, showing a decrease in percentage of retrieved segments during the active state on day 2 . Since not all segments of the separate behavioral states were available for analysis, no hard conclusions can be drawn from these results. However, we believe that together with previously reported literature these results support the evidence that the decrease in fHRV values on day 2 is caused by a decrease in fetal activity following betamethasone administration.

Two additional factors known to influence fHRV are gestational age and diurnal rhythms. In healthy fetuses, LTV and STV increase with increasing gestational age, whereas basal fHR decreases [34]. LF- and HF-power significantly increase during pregnancy [9]. All fetuses included in our study have a gestational age between $24^{+4}$ and $33^{+4}$ weeks. We measured each fetus on successive days and looked at relative changes in fHRV parameters. Therefore, the influence of this gradual increase in fHRV parameters during gestation is likely to be minor.

Fetal diurnal states have been described starting from 22 weeks of gestation $[39,40]$. Normal fetal diurnal rhythm shows an increase in fHRV in the afternoon and evening compared to the morning. Previous research found this increase in fHRV during the course of the day to be absent on day 2 after betamethasone administration [36,41]. A correlation between the time of day of the measurement and the fHRV values on day 2 was also absent in our results. To reduce the influence of diurnal variation within our study, we fixed the timing of measurements within a series between 20 and $28 \mathrm{~h}$ after the previous measurement.

During our study period, participants received pregnancy-related drugs other than betamethasone. Since in daily clinical practice betamethasone, for threatened preterm delivery, is rarely administered without tocolytics, studying the effects of corticosteroids in patients without co-medication is not feasible. Verdurmen et al. previously reviewed the literature concerning the effects of tocolytic drugs on HRV [42]. They found that nifedipine and atosiban had no significant effect on fHRV. There is no literature available on the effect of indomethacin on fHRV, but an effect on fHRV parameters is unlikely given its mechanism of action. This is also the case for the remaining concomitant medication such as antibiotics, progesterone, insulin and anticoagulants.

\section{Conclusion}

Fetal HRV parameters show a decreasing trend on day 2 after betamethasone administration, both in the time- and frequency-domain. This decrease was significant for STV and HF-power. The reported changes in fHRV parameters are likely due to a drug-induced decrease in fetal activity, rather than a sign of fetal distress. All fHRV parameters return to baseline values on day 4 after betamethasone treatment is started.

\section{Conflict of interest statement}

L. Noben: none declared.

K.M.J. Verdurmen: none declared.

G.J.J. Warmerdam: G.J.J. Warmerdam is a former employee of Nemo Healthcare.

R. Vullings: R. Vullings is shareholder in Nemo Healthcare BV.

S.G. Oei: none declared.

J.O.E.H. van Laar: none declared.

\section{Declarations of interest}

R. Vullings is shareholder in Nemo Healthcare BV. 


\section{References}

[1] D. Roberts, J. Brown, N. Medley, S. Dalziel, Antenatal corticosteroids for accelerating fetal lung maturation for women at risk of preterm birth (review), Cochrane Database Syst. Rev. 1 (3) (2017) 1-273.

[2] E.J.H. Mulder, J.B. Derks, M.F. Zonneveld, H.W. Bruinse, G.H.A. Visser, Transient Reduction in Fetal Activity and HRV After Maternal Betamethasone administration.pdf, (1994), pp. 49-60.

[3] J.B. Derks, E.J.H. Mulder, G.H.A. Visser, The effects of maternal betamethasone administration on the fetus.pdf, Br. J. Obstet. Gynaecol. 102 (1995) 40-46.

[4] E.J. Mulder, J.B. Derks, G.H. Visser, Antenatal corticosteroid therapy and fetal behaviour: a randomised study of the effects of betamethasone and dexamethasone, Br. J. Obstet. Gynaecol. 104 (11) (1997) 1239-1247 [Internet]. Available from: http://www.ncbi.nlm.nih.gov/pubmed/9386023.

[5] L.A. Magee, G.S. Dawes, M. Moulden, C.W. Redman, A randomised controlled comparison of betamethasone with dexamethasone: effects on the antenatal fetal heart rate, Br. J. Obstet. Gynaecol. 104 (November) (1997) 1233-1238.

[6] M.V. Senat, S. Minoui, O. Multon, H. Fernandez, R. Frydman, Y. Ville, Effect of dexamethasone and betamethasone on fetal heart rate variability in preterm labour: a randomised study, Br. J. Obstet. Gynaecol. 105 (7) (1998) 749-755 [Internet]. Available from http://www.ncbi.nlm.nih.gov/pubmed/9692416.

[7] R.H. Paul, A.K. Suidan, S. Yeh, B.S. Schifrin, E.H. Hon, Clinical fetal monitoring. VII. The evaluation and significance of intrapartum baseline FHR variability, Am. J. Obstet. Gynecol. 123 (2) (Sep 1975) 206-210.

[8] Heart rate variability. Standards of measurement, physiological interpretation, and clinical use. Task Force of the European Society of Cardiology and the North American Society of Pacing and Electrophysiology, Eur. Heart J. 17 (3) (1996 Mar) 354-381.

[9] J.O.E.H. van Laar, G.J.J. Warmerdam, K.M.J. Verdurmen, R. Vullings, C.H.L. Peters, S. Houterman, et al., Fetal heart rate variability during pregnancy, obtained from non-invasive electrocardiogram recordings, Acta Obstet. Gynecol. Scand. 93 (1) (2014 Jan) 93-101.

[10] S. Rhose, A.M.F. Heinis, F. Vandenbussche, J. van Drongelen, J. van Dillen, Interand intra-observer agreement of non-reassuring cardiotocography analysis and subsequent clinical management, Acta Obstet. Gynecol. Scand. 93 (6) (2014 Jun) 596-602.

[11] K.M.J. Verdurmen, G.J.J. Warmerdam, C. Lempersz, A.D.J. Hulsenboom, J. Renckens, J.P. Dieleman, et al., The influence of betamethasone on fetal heart rate variability, obtained by non-invasive fetal electrocardiogram recordings, Early Hum. Dev. 119 (2018) 8-14 [Internet]. (March 2017). Available from: https://doi. org/10.1016/j.earlhumdev.2018.02.011.

[12] J.G. Nijhuis, H.F. Prechtl, C.B.J. Martin, R.S. Bots, Are there behavioural states in the human fetus? Early Hum. Dev. 6 (2) (Apr 1982) 177-195.

[13] J. Karin, M. Hirsch, S. Akselrod, An estimate of fetal autonomic state by spectral analysis of fetal heart rate fluctuations, Pediatr. Res. 34 (2) (1993) 134-138.

[14] J.O.E.H. van Laar, C.H.L. Peters, R. Vullings, S. Houterman, S.G. Oei, Power spectrum analysis of fetal heart rate variability at near term and post term gestation during active sleep and quiet sleep, Early Hum. Dev. 85 (12) (Dec 2009) 795-798.

[15] M. Cesarelli, M. Romano, P. Bifulco, Comparison of short term variability indexes in cardiotocographic foetal monitoring, Comput. Biol. Med. 39 (2) (2009 Feb) $106-118$.

[16] C.M. van Ravenswaaij-Arts, L.A. Kollee, J.C. Hopman, G.B. Stoelinga, H.P. van Geijn, Heart rate variability, Ann. Intern. Med. 118 (6) (Mar 1993) 436-447.

[17] S. Akselrod, D. Gordon, F.A. Ubel, D.C. Shannon, A.C. Berger, R.J. Cohen, Power spectrum analysis of heart rate fluctuation: a quantitative probe of beat-to-beat cardiovascular control, Science 213 (4504) (Jul 1981) 220-222.

[18] J. Karin, M. Hirsch, S. Akselrod, An estimate of fetal autonomic state by spectral analysis of fetal heart rate fluctuations, Pediatr. Res. 34 (2) (Aug 1993) 134-138.

[19] K.M.J. Verdurmen, J. Renckens, J.O.E.H. van Laar, S.G. Oei, The influence of corticosteroids on fetal heart rate variability: a systematic review of the literature, Obstet. Gynecol. Surv. 68 (12) (2013 Dec) 811-824.

[20] M. Varanini, G. Tartarisco, L. Billeci, A. Macerata, G. Pioggia, R. Balocchi, An efficient unsupervised fetal QRS complex detection from abdominal maternal ECG, Physiol. Meas. 35 (8) (Aug 2014) 1607-1619.

[21] G.J.J. Warmerdam, R. Vullings, L. Schmitt, J.O.E.H. van Laar, J.W.M. Bergmans, Hierarchical probabilistic framework for fetal R-peak detection, using ECG waveform and heart rate information, IEEE Trans. Signal Process. 66 (16) (2018) 4388-4397 [Internet]. Available from: http://ieeexplore.ieee.org/stamp/stamp. jsp?tp $=$ \&arnumber $=8404121$ \&isnumber $=8399517$.

[22] M.J. Rooijakkers, C. Rabotti, S.G. Oei, M. Mischi, Low-complexity R-peak detection for ambulatory fetal monitoring, Physiol. Meas. 33 (7) (2012 Jul) 1135-1150.

[23] C. Peters, R. Vullings, J. Bergmans, G. Oei, P. Wijn, The effect of artifact correction on spectral estimates of heart rate variability, Conf. Proc. IEEE Eng. Med. Biol. Soc. 2008 (2008) 2669-2672.

[24] J.O.E.H. van Laar, C.H.L. Peters, S. Houterman, P.F.F. Wijn, A. Kwee, S.G. Oei, Normalized spectral power of fetal heart rate variability is associated with fetal scalp blood pH, Early Hum. Dev. 87 (4) (Apr 2011) 259-263.

[25] N.A.M. de Beer, P. Andriessen, R.C.M. Berendsen, S.G. Oei, P.F.F. Wijn, S.B. Oetomo, Customized spectral band analysis compared with conventional Fourier analysis of heart rate variability in neonates, Physiol. Meas. 25 (6) (Dec 2004) 1385-1395.

[26] S.W. Min, H. Ko, C.S. Kim, Power spectral analysis of heart rate variability during acute hypoxia in fetal lambs, Acta Obstet. Gynecol. Scand. 81 (11) (2002) 1001-1005.

[27] J.O.E.H. Van Laar, M.M. Porath, C.H.L. Peters, S.G. Oei, Spectral analysis of fetal heart rate variability for fetal surveillance: review of the literature, Acta Obstet. Gynecol. Scand. 87 (3) (2008) 300-306.

[28] G. Magenes, M.G. Signorini, D. Arduini, Classification of cardiotocographic records by neural networks, Proceedings of the IEEE-INNS-ENNS International Joint Conference on Neural Networks IJCNN 2000 Neural Computing: New Challenges and Perspectives for the New Millennium. Como, Italy, 2000, pp. 637-641.

[29] J. Pardey, M. Moulden, C.W.G. Redman, A computer system for the numerical analysis of nonstress tests, Am. J. Obstet. Gynecol. 186 (5) (May 2002) 1095-1103.

[30] A. Malliani, F. Lombardi, M. Pagani, Power spectrum analysis of heart rate variability: a tool to explore neural regulatory mechanisms, Br. Heart J. 71 (1994) 1-2.

[31] M.S. Lunshof, K. Boer, H. Wolf, S. Koppen, J.K. Velderman, E.J.H. Mulder, Shortterm $(0-48 \mathrm{~h})$ effects of maternal betamethasone administration on fetal heart rate and its variability, Pediatr. Res. 57 (4) (2005) 545-549.

[32] D. Subtil, P. Tiberghien, P. Devos, D. Therby, G. Leclerc, P. Vaast, et al., Immediate and Delayed Effects of Antenatal CCS on FHR.pdf, (2003), pp. 524-531.

[33] E.J.H. Mulder, J.B. Derks, G.H.A. Visser, Effects of antenatal betamethasone administration on fetal heart rate and behavior in twin pregnancy, Pediatr. Res. 56 (1) (2004) 35-39.

[34] I.J. Nijhuis, J. ten Hof, E.J. Mulder, J.G. Nijhuis, H. Narayan, D.J. Taylor, et al., Fetal heart rate in relation to its variation in normal and growth retarded fetuses, Eur. J. Obstet. Gynecol. Reprod. Biol. 89 (1) (Mar 2000) 27-33.

[35] S. Rotmensch, M. Liberati, T.H. Vishne, C. Celentano, Z. Ben-Rafael, U. Bellati, et al., The effect of betamethasone and dexamethasone on fetal heart rate patterns and biophysical activities A prospective randomized trial, Acta Obstet. Gynecol. Scand. 78 (6) (1999) 493-500 [Internet]. Available from: http://www.ncbi.nlm. nih.gov/pubmed/10376858.

[36] S.V. Koenen, E.J.H. Mulder, L.D. Wijnberger, G.H.A. Visser, Transient loss of the diurnal rhythms of fetal movements, heart rate, and its variation after maternal betamethasone administration, Pediatr. Res. 57 (5 I) (2005) 662-666.

[37] B.J. Cohlen, R.H. Stigter, J.B. Derks, E.J. Mulder, G.H. Visser, Absence of significant hemodynamic changes in the fetus following maternal betamethasone administration, Ultrasound Obstet. Gynecol. 8 (4) (Oct 1996) 252-255.

[38] S. Shenhav, M. Volodarsky, E.Y. Anteby, O. Gemer, Fetal acid-base balance after betamethasone administration: relation to fetal heart rate variability, Arch. Gynecol. Obstet. 278 (4) (Oct 2008) 333-336.

[39] M. Pillai, D. James, The development of fHR patterns during pregnancy, Obstet. Gynecol. 76 (5) (1990) 812-816.

[40] J.I. de Vries, G.H. Visser, E.J. Mulder, H.F. Prechtl, Diurnal and other variations in fetal movement and heart rate patterns at 20-22 weeks, Early Hum. Dev. 15 (6) (Nov 1987) 333-348.

[41] R. de Heus, E.J.H. Mulder, J.B. Derks, S.V. Koenen, Visser GHA, Differential effects of betamethasone on the fetus between morning and afternoon recordings, J. Matern. Fetal Neonatal Med. 21 (8) (2008) 549-554 [Internet]. Available from: http://www.ncbi.nlm.nih.gov/pubmed/18609360.

[42] K.M.J. Verdurmen, A.D.J. Hulsenboom, J.O.E.H. van Laar, S.G. Oei, Effect of tocolytic drugs on fetal heart rate variability: a systematic review, J. Matern. Fetal Neonatal Med. 30 (20) (2017) 2387-2394. 